\title{
Tracking the degree of disequilibrium during magma ascent and reheating
}

\author{
PhilipP Ruprecht ${ }^{1}$, Ellyn G. HugGins ${ }^{1}$, MARK S. \\ GHIORSO $^{2}$ \\ ${ }^{1}$ Dept. Geological Sciences \& Engineering, Univ. of Nevada, \\ Reno, NV 89557, USA (*correspondence: \\ pruprecht@unr.edu, eghuggins@nevada.unr.edu) \\ ${ }^{2}$ OFM Research, Redmond, CA, United States
}

Most volcanic systems are open to mass and heat exchange. E.g., magmatic recharge and eruption distrupts a magma's approach to equilibrium. During such episodes of unrest, intensive parameters (pressure, temperature, and composition) are rapidly changing and kinetic timescales become increasingly important when interpreting the crystal chemical record and textural evolution. In the case of recharge-driven reheating and subsequent decompressiondriven magma degassing, the respective thermodynamic responses are of opposite direction. Thus, combined reheating and decompression may lead to only small changes in crsytallinity and partially suppress microlite growth, a texture that is commonly interpreted to represent rapid magma ascent with a kinetic limit to crystal growth. In both scenarios (reheating-decompression vs. rapid ascent) the ascent rate is a critical variable. Reheating and decompression extends the window of ascent paths to lower ascent rates compared to a purely kinetic control, while still producing magmas with limited crystal growth or dissolution. This may have significant implications for models of magma ascent and eruption dynamics.

We explore the thermodynamic response of a silicic system using the chemical affinities of plagioclase during reheating follwed by decompression via MELTS. For a range in ascent rates we calculate the cumulative changes in chemical affinity of plagioclase during ascent. The chemical affinities are directly proportional to growth (and dissolution) rates and therefore provide a measure for predicted growth (dissolution) on ascent. While the model does not distinguish between microlite growth or crystallization on existing crystals, we can only determine how much the bulk crystallinity changes on ascent. Our model predicts that ascent rates of $0.002-0.006 \mathrm{MPa} / \mathrm{s}(\sim 0.08-0.25 \mathrm{~m} / \mathrm{s})$ will largely balance the drivers for growth (degassing) and dissolution (reheating) for ascent from $200 \mathrm{MPa}$ and reheating by $50-70^{\circ} \mathrm{C}$. Small degrees of heating are difficult to detect petrologically; therefore such effects are easily missed when interpreting silicic eruption products. 